\title{
0 INTERUNIVERSITY STUDY PROGRAM NA UNIVERSIDADE DE SÃO PAULO
}

José Carlos Sebe Bom Meihy 
I - No espaço deste artigo procurou-se avaliar o significado do Interuniversity Study Program no Brasil (ISP) enquanto uma experiência educacional desenvolvida juntamente com a Universidade de São Paulo. Neste exame repontam aspectos políticos, critérios educacionais e maneiras de entendimento do papel universitário em face de contextos culturais diversos. Considerando-se que, desde o estabelecimento dos primeiros contatos até o presente, são decorridos quase 15 anos, a aventura do ISP-USP já descreveu uma trajetória gravada na vida dos dois pólos institucionais.

A USP, desde 1934, tem primado por um amplo relacionamento universitário com diversas partes do mundo, principalmente com a Europa. Depois das importantes missões culturais vindas para o estabelecimento da Universidade, afloraram muitos acordos que, contudo, decorriam sempre da iniciativa de docentes específicos e de Departamentos, escapando gradativamente da iniciativa da administração central da Universidade. Com o passar dos anos e motivada pela crescente falta de estabelecimento de diretrizes para qualquer orientação político-educacional para países estrangeiros, a USP passou a se responsabilizar pela efetivação de alguns projetos educacionais decididos fora dos interesses da comunidade acadêmica.

No caso dos docentes e Departamentos, a vinculação com instituições internacionais e com pesquisadores espelhava sempre interesses científicos, independentes de uma proposta política universitária. $\mathrm{Na}$ segunda alternativa impunha-se uma tarefa nem sempre clara para a comunidade uspiana, que se via obrigada a conviver com atitudes político-culturais não óbvias. De qualquer forma, a USP funcionava mais como local do recebimento de grupos estrangeiros do que ponto de envio de acadêmicos brasileiros para fora do país. Além do que, nacionalmente, não existiam facilitações promovidas por agências financiadoras de pesquisas que pudessem operar no sentido da ajuda, para que a USP tirasse melhores proveitos dos acordos internacionais. Talvez aí houvesse nascido a expressão que coloca a USP como "vítima dos convênios" e, na mesma medida, dado razões para a manutenção entre nós, de uma certa mentalidade conservadora frente aos convênios.

Em decorrência da perda de força dos Orgãos Centrais da USP em face dos acordos internacionais, o que se observa é que uma con- 
duta burocratizante se estabeleceu pensando os convênios apenas como uma questão de forma legal, destituída de posturas de interesses comunitários e educacionais. Como nestes anos todos de Universidade, entre nós não ganhou corpo expressivo nenhum tipo de núcleo de estudo efetivamente voltado à educação internacional, há uma explicação para o nível mínimo em que nos encontramos. Educação internacional tantas vezes é apenas uma referência perdida em cursos teóricos repartidos por diversos Departamentos. Como não temos um programa eficiente de "Relações Internacionais", o horizonte das possibilidades fica restrito a iniciativas localizadas e a experiência de "estudar fora" passa a ser privilégio de poucos, um diferenciador elitista entre as levas de professores e estudantes.

No momento, há uma tendência positiva da USP em se ferir o "problema dos convênios" e muitas esperanças são depositadas em cima dos eventuais esforços para o entendimentos dos acordos internacionais como um processo educativo, coerente com a formação acadêmica e compatível com os interesses nacionais.

A existência de um exclusivismo administrativo e burocratizante no reino dos convênios internacionais da USP limita vôos mais amplos. A percepção de modos indecisos da USP se convencionar tem produzido, além dos personalismos expressos em estabelecimento de acordos mal gerenciados, o surgimento de um independentismo inconseqüente e desmedido. Os centralismos acontecidos por não considerarem o efeito educacional dos programas internacionais e por não colocar em nenhuma proposta política no lugar, apenas têm aperfeiçoado a burocratização vazia.

Contra o centralismo, sempre legalista e apoiado na perfeição formal, propõe-se a coordenação. Por coordenação pretende-se penSàr em um órgão inteligente que interprete os convênios na moldura da educação internacional, legitimamente colocada em princípios de uma política cultural a ser estabelecida. Fala-se em propostas largas que sem anular a iniciativa de professores, Departamentos ou Centros de Estudos, abriguem um vanguardismo que abra caminhos novos para a Universidade.

Neste panorama é de se enfrentar, sem tantos preconceitos, algumas questões iniciais e básicas: qual seria a opção internacionalista da USP? Pautar-se mais claramente na direção do Terceiro Mundo? Definir-se por uma paralelização primeiro-mundista? Combinar am- 
bas? De qualquer forma, derrubar o abusivo administrativismo atual exige opções que demandam maneiras político-culturais de contemplar a vitalidade acadêmica. Pouco ou nada adianta a criação de grupos de estudos de convênios se eles não se traduzem em propostas. Sem um projeto de atuação, legitimado pela comunidade, estes organismos, mesmo constantemente repostos, são meros elementos burucratizantes, antipáticos e pouco eficientes.

Estas reflexões são resultados do acompanhamento, por dez * anos; das circunstancialidades que envolvem alguns dos programas internacionais da USP Primeiramente como colaborador, depois como diretor (desde 1979), pude seguir de perto situações que circunscreveram as relações entre o Interuniversity Study Program e a Universidade dê São Paulo.

11 - O ISP-USP: “campus avançado"

A história deste convênio começou em 1972. Por este tempo abria-se nacionalmente uma fase de falso desenvolvimento e, para o mundo, o Brasil se mostrava como um modelo econômico-político eficaz. A importância de nosso país como exemplo de progresso nos projetava a nível do interesse internacional. A USP, por outro lado, descortinava uma paisagem acadêmica capaz de mostrar-se como sinônimo do desenvolvimento. Afinal, os atos repressivos que "sanearam" o país também passaram pela USP tolhendo, em muito, a crítica acadêmica, as oposições e vozes antagônicas ao regime.

Coincidindo com um momento de expansão do regime universitário norte-americano, que desde os anos 60 acolhia os filhos do baby boom que seguiu a Segunda Guerra Mundial, o Brasil, bem como alguns outros países da América Latina (México, Argentina, Chi(e), passava a ser considerado como nova área de estudo.

O professor Ricardo Paiva, nascido brasileiro, professor de Literatura da Universidade de Indiana, Campus de Bloomington, estado de Indiana, Estados Unidos, foi a peça básica inicial para o estabelecimento do que hoje é o ISP-USP Depois dos primeiros contatos mantidos diretamente com o reitor Miguel Reale, assessorado por professores do Centro de Estudos Portugueses e do Instituto de Estudos Brasileiros (IEB), intensificou-se a conversação para que em 1973 pudesse vir a primeira turma de alunos deste programa de estudos, desenhado para um ano de duração. 
Por este tempo, a crise econômica mundial caracterizou como. caóticas as relações internacionais; contudo, o Brasil contrariamente se exibia como exceção apoiado na aparência do milagre econômico. Também aturdido pela continuidade da Revolução Cubana de 59, os Estados Unidos buscaram entender melhor os países do sul continental, estabelecendo pontes facilitadoras de conhecimentos. Junto aos iinteresses acadêmicos, outros, políticos, excitavam a imaginação universitária para avançar em mais uma "área de estudos". É preciso afirmar que coerentemente com a visão anglo-saxônica do mundo, os Estados Unidos organizam seus currículos segundo "estudos de áreas", geograficamente localizadas.

Guiada pela iniciativa de Paiva, institucionalizou-se a formação do convênio. O texto oficial deste acordo deixava clara a distinção dos objetivos das partes. De um.lado, a Universidade de Indiana mandando uma média de 15 estudantes e, de outro, a USP enviando um docente para aperfeiçoamento da carreira e um estudante de pós-graduação para complementar pesquisa e ensinar português. Desde logo ficava patente as diferenças no entendimento da reciprocidade.

Pelo lado estadunidense, o acordo foi estabelecido como uma extensão do campus norte-americano, exposto a outra paisagem. Para tanto, a administração do acordo foi sempre provida pela Universidade de Indiana, materializando a concepção de "campus avançado" no Brasil. No caso dos diretores do programa, até 1979 todos eram professores da Universidade de Indiana (Ricardo Paiva, 1973-76, Claus Clüver, 76-77 e Carlos S. Bakota, 77-78). Os demais membros do staff eram também pagos e definidos por Indiana. Mantinha-se com esta forma administrativa a mesma estrutura universitária norte-americana e a visão do Brasil que filtrava, raramente fugia da exemplificação de casos. Em outras palavras, quase sempre a USP era uma paisagem cultural diferente para estudantes, que mantinham aqui a mesma ordenação de aprendizado da escola de lá.

As relações oficiais com a USP, especificadas segundo as exigências da I.U. acolhidas pela cúpula da USP, delegavam à instituição norte-americana as decisões sobre o destino e andamento do programa. A USP se representava então pelo IEB que servia como hospedeiro do acordo. Cabia ainda a esta instituição prover o programa de um escritório e a responsabilidade de decisão sobre os bolsistas. 
Com o fluir do tempo, outras universidades norte-americanas, através de Indiana, começaram a integrar o programa uspiano. A participação das academias dava início ao que seria mais tarde um consórcio de universidades, coligadas para operar no exterior Esta era, aliás, a tendência geral das grandes escolas norte-americanas que insistem em que os estudantes sempre tenham a experiência de estudos no exterior, como parte regular do processo da educação. O sistema de colegiado (que se vulgarizava nos Estados Unidos) em face do convênio com a USP deu passagem ao que mais tarde seria o Interuniversity Study Program no Brasil. Dentre os grupos educacionais norte-americanos que integraram o acordo de Indiana, desde 1974, estava o sistema da Califórnia, o mais poderoso órgão estadunidense de programas no exterior.

A tênue consistência do milagre econômico brasileiro desfazia-se com rapidez e com ela a euforia do estabelecimento do programa da Universidade de Indiana. Despesas de manutenção do programa assustavam. Na mesma medida, a USP apenas se propunha a fornecer aulas e escritórios. Em 1977 a crise econômica mundial provocava, além da recessão, a falência total do Brasil enquanto modelo econômico. Para a Universidade de Indiana, como para todo o surto de programas floridos nos primórdios dos anos 70 , a diminuição de interesse por estudar no Brasil se manifestava em crescentes dificuldades para se recrutar estudantes para virem para cá. As únicas saídas para Indiana seriam ou findar o programa ou passar para outros o contrato.

Pelo lado brasileiro, havia também inúmeros problemas a serem enfrentados. Os anos de recrudescimento e afirmação da ditadura militar haviam provocado, com justiça, uma aversão aos Estados Unidos, particularmente depois do conhecimento das denúncias, em 75, da "Operação Brother Sam" O programa de Indiana era visto simplisticamente como uma reprodução automática do sistema capitalista e, portanto, como braço da ação imperialista norte-americana. As repulsas se multiplicavam e poucos não foram os estudantes que sentiram diretamente estas rejeições. Todo o ímpeto defensivo nutrido no campus contra a política estadunidense refletia-se em crítica negativa, dificultando o relacionamento do programa com a comunidade.

Nos Estados Unidos a administração do convênio foi oferecida à Universidade de Califórnia, especificamente ao Education Abroad Program (EAP), órgão especialmente ordenado para efetivar progra- 
mas de estudo em diferentes partes do mundo. Na visão da Universidade de Califórnia seria importante participar do programa no Brasil, mas era inviável mantê-lo, pois as despesas gerais faziam do acordo com a USP um risco. Ademais, a USP não possuía adequados cursos de português para estrangeiros, não tinha como equiparar sistemas de avaliações diferentes, mecanismos para tratar com estudantes estrangeiros em caso de greve, secretários-bil íngües, etc. Além disso, era claramente incompativel com o IEE a responsabilidade pela formação acadêmica de estudantes norte-americanos.

Coparticipantes de outras atividades similares no exterior, a Universidade de Stanford (SU), também da Califórnia, foi motivada a presidir um comitê que então assumia, com riscos repartidos, o mesmo convênio anterior, procurando modificá-lo segundo conveniências de ambas, tanto da USP quanto do lado norte-americano. Havia na iniciativa stanfordiana um compromisso de não abandonar por completo os programas que se extinguiam na América Latina. Pensava-se que talvez o programa do Brasil pudesse acolher mais estudantes $\mathrm{e}$ representar uma sobrevivência dos velhos contatos. Em fins de 78, algumas universidades norte-americanas aderiram ao convênio: Universidade de Nova York (Stony Brook), Universidade de Wisconsin, John's Hoppkins, ao lado de Indiana, Califórnia e Stanford. Ainda que o texto do acordo se mantivesse o mesmo, a experiência do consórcio resultava num esforço de continuidade.

Até o presente, o comitê do ISP continua a ser presidido por Stanford com a participação das outras Universidades que compõem o grupo. Anualmente há um encontro onde se decidem as linhas de atuação do ISP. Sem ser identificada como promotora do programa, Stanford se responsabiliza por toda a coordenação do programa, funcionando como ponto central de informações e comunicação. A USP, não mais pelo IEB, e sim pela Coordenadoria de Atividades Didáticas Acadêmicas e Culturais, gere o programa do lado brasileiro.

III - O ISP-USP: epicentro brasileiro

Com base no mesmo texto contratual de Indiana, o ISP pretendeu se adequar às novas maneiras de gerir o programa e se adaptar às poucas solicitações da USP A nível teórico, em contraposição ao conceito de "campus avançado", inclusive por sugestão dos estudantes envolvidos no programa, propôs-se a concepção de "universidade hospedeira" isto é, o princípio que privilegia os valores da universi- 
dade que recebe o programa, em detrimento dos padrões da parte internacional.

Se, no caso do "campus avançado", mantinha-se o staff original norte-americano, isto implicava em um uso continuado do uso da língua inglesa e na manutenção da estrutura educacional estadunidense. Na situação de "universidade hospedeira" a língua oficial deveria ser português e todos os funcionários, brasileiros. A idéia é que vigorando o conceito de "universidade hospedeira" haveria o aproveitamento mais completo da cultura do país que recebe o programa e das propostas da universidade que $\mathrm{o}$ abriga. $\mathrm{O}$ fato do diretor do programa ser um docente da USP, empregado em tempo parcial, pareceu favorável à medida que facilitava a integração do programa junto a comunidade local.

Indicado um diretor brasileiro, em agosto de 1979, iniciava-se uma longa e complexa discussão com dirigentes do IEB e da CODAC, que, então, centralizava os convênios. $A$ duplicidade da gestão do convênio, numa fase de transição da USP, entre o IEB e a CODAC, atrapalhou muito as negociações. No centro da discussão estava a ampliação do acordo. Desde que o programa da USP era dos poucos sobreviventes, pensava-se que outros fatores como troca de livros das editoras universitárias congregadas, microfilmagem de documentação útil a pesquisas, congressos comuns, pudessem fazer parte do acordo, resultando em benefícios para ambos os lados.

Um problema, desde logo, travou o andamento das transformações propostas: a não seqüência, por parte da USP, das negociações. A reposição constante de coordenadores da CODAC e a ausência de uma orientação político-acadêmica para convênios, empobreceu as possibilidades. Isto complicava o quadro geral das relações, pois outra questão se desdobrava neste instante. Afinal de quem era o programa? De um lado, o ISP financiava a manutenção do programa, recrutava alunos, promovia novas propostas e favoreceu por 3 vezes a ida do pessoal da administração da USP para estudar o caso e apresentar um novo acordo. A USP sentia-se "dona" do programa, pois oferecia a ótima oportunidade de estudo em seus cursos e o escritório. A ambigüidade fez com que algumas formas alternativas de reciprocidade se fizessem independentes de um novo acordo. De qualquer forma, há no momento um esforço de estabelecimento de novas fases para esta experiência acadêmica. 


\section{IV - A questão da continuidade}

No momento, a Universidade de São Paulo começa a articular uma política internacional de educação, que se afigura como positiva.

Contatos novos e revisões de velhos acordos situam-se no horizonte das preocupações da cúpula uspiana.

Por outro lado, o momento é também de reavaliação para o ISP posto que os 15 anos de aproximação com a USP Ihe ensinaram muito quanto à validade deste acordo.

No instante em que a USP se propõe a promover melhores condições para a realização direta dos convênios com as universidades congregadas do ISP, espera-se que esta postura se enquadre na formulação mais ampla da política de educação da Universidade. 


\section{FICHA CATALOGRAFICA}

MEIHY, José Carlos Sebe Bom. O Interuniversity Study Program na Universidade de Säo Paulo. Reviste da Universidade de SEo Paulo. São Paulo, (4): p. 43 - 52. março de 1987. 